\title{
LA EXPEDICIÓN BOTÁNICA EN LOS TEXTOS ESCOLARES DE COLOMBIA 1974-2008
}

\author{
Diana Soto Arango 1 \\ Universidad Pedagógica y Tecnológica de Colombia \\ Grupo de investigación IL $A C$ \\ dianaelvirasoto@gmail.com
}

Recepción: 27/04/2010

Evaluación: 25/10/2010

Aceptación: 22/06/2011

Artículo de Reflexión

\section{RESUMEN}

Se presenta el análisis de los mensajes que vehiculan los textos escolares, de ciencias sociales, en la educación básica primaria y secundaria, sobre los imaginarios que identifican la historia cultural de la colonia en especial el referente a la expedición Botánica, dentro del movimiento cultural de la Ilustración, y la relación de esta con la Independencia americana. El análisis se enmarca dentro de la legislación de Colombia, de los tres períodos que comprende la investigación. El método se circunscribe dentro de la corriente historiográfica de la historia social de la educación comparada y en concreto en la tendencia de análisis de textos escolares bajo los indicadores de: conceptualización de la ilustración y expedición botánica; relevancia de la expedición en el inicio de la ciencia en Colombia y los vínculos con la independencia;

\footnotetext{
${ }^{1}$ Profesora titular de la Universidad Pedagógica y Tecnológica de Colombia máxima categoría. Posdoctorado realizado en el Consejo Superior de Investigaciones Científicas de España del 12 de julio de 1993 a diciembre de 1995. Doctora en Ciencias de la Educación. UNED, España, 1987. Máster en Investigación Socio-educativa. Universidad Pedagógica Nacional. 1978. Licenciada Psicología Educativa y Administración. Universidad Pedagógica y Tecnológica de Colombia. 1973. Licenciada Ciencias de la Educación. UNED. España. 1984. Organizó en 1996 y fue la primera Directora del Doctorado en Ciencias de la Educación de RUDECOLOMBIA, Organizó en 1992 la Sociedad de Historia de la Educación Latinoamericana es Codirectora del Grupo de Investigación: "Historia y Prospectiva de la Universidad Latinoamericana"- HISULA A1 y el grupo la "Ilustración en América Colonial" - ILAC A1, de los cuales es directora. Miembro correspondiente de la Academia de Historia de Colombia.
} 
figuras de científicos relevantes; aportación a la identidad nacional, actividades didácticas. En la iconografía se establece la tipología de las figuras de Mutis, colaboradores y de plantas. Los resultados se enmarcan en la poca relevancia en los contenidos y la iconografía de la Expedición Botánica. En la conclusión se estableció que en los períodos de estudio varían los diseños de los textos y los contenidos.

Palabras clave: Revista Historia de la Educación Latinoamericana, expedición botánica, independencia, ilustración, Mutis.

\title{
THE BOTANICAL EXPEDITION IN THE SCHOOL BOOKTEXTS IN COLOMBIA 1974-2008
}

\author{
Diana Soto Arango \\ Universidad Pedagógica y Tecnológica de Colombia \\ Research Group ILAC \\ dianaelvirasoto@gmail.com
}

\begin{abstract}
It is presented the analysis of the messages that have in implicitly way the school textbooks, of social sciences, in the basic primary and secondary education, on the imaginary ones who identify the cultural history of the colony, especially the modal to the Botanical expedition, inside the cultural movement of the Illustration, and the relation of this one with the American Independence. The analysis places inside the legislation of Colombia of three periods that understands the investigation. The method limits itself inside the current history-graphic of the social history of the compared education and its makes a concrete in the trend of analysis of school texts under the indicators of: conceptualization of the illustration and botanical expedition; relevancy of the expedition in the beginning of the science in Colombia and the links with the independence; figures of relevant scientists; contribution to the national identity, didactic activities. In the iconography there is established the typology of the figures of Mutis, collaborators and of plants. The results place in small relevancy in the contents and the iconography of the Botanical Expedition. In the conclusion it was found that in the periods of study they change the designs of the texts and the contents.
\end{abstract}

Key words: Journal of Latin American Education History, botanical expedition, independence, enlightenment, Mutis. 


\title{
A EXPEDIÇÃO BOTÂNICA NOS TEXTOS ESCOLARES DA COLÔMBIA 1974-2008
}

\author{
Diana Soto Arango \\ Universidade Pedagógica e Tecnológica da Colômbia \\ Grupo de pesquisa IL AC \\ dianaelvirasoto@gmail.com
}

\section{RESUMO}

Apresenta-se a análise das mensagens que veiculam os textos escolares, de ciências sociais, na educação básica primária e secundária, sobre os imaginários que identificam a história cultural da colônia, especialmente a referente à expedição Botânica, dentro do movimento cultural da ilustração e a relação desta com a Independência americana. A análise volta-se à legislação da Colômbia, nos três períodos que abrange a pesquisa. $\mathrm{O}$ método de circunscreve dentro da corrente historiográfica da história social da educação comparada e em concreto na tendência de análise de textos escolares sob indicadores de: conceituação da ilustração e expedição botânica; relevância da expedição no início da ciência na Colômbia e os vínculos com a independência; figuras de científicos relevantes; contribuição à identidade nacional, atividades didáticas. $\mathrm{Na}$ iconografia se estabelece a tipologia das figuras típicas de Mutis, colaboradores e de plantas. Os resultados apresentam a pouca relevância dos conteúdos e a iconografia da Expedição Botânica. A conclusão estabeleceu que, nos períodos de estudo, variam os desenhos dos textos e os conteúdos.

Palavras chaves: Revista História da Educação Latino-americana, expedição botânica, independência, ilustração, Mutis. 


\section{INTRODUCCIÓN}

La Expedición Botánica, aprobada en 1783, es el hecho culturalcientífico más relevante, que se realizó en el período colonial del virreinato de la Nueva Granada, en el siglo XVIII dentro del contexto cultural de la Ilustración. Esta Expedición agrupo a la élite Ilustrada neogranadina. Con la muerte de Mutis en 1808 y el envío de las láminas a la metrópoli en 1816, más los hechos de la independencia, esta labor quedó truncada. La misma figura de José Celestino Mutis (1732-1808) se fue perdiendo en el tiempo. El primer centenario de su nacimiento (1832) y muerte (1908) pasó desapercibido al igual que el primer centenario de la Expedición Botánica (1883). Sin embargo, la situación cambia para los bicentenarios de su nacimiento y de la Expedición Botánica.

Precisamente, en este trabajo, producto del proyecto de investigación "La independencia americana. Textos, enseñanza e imaginarios escolares en Colombia y España" se presenta como objetivo el analizar los mensajes que vehiculan los textos escolares de ciencias sociales, en la educación básica primaria y secundaria, enmarcados dentro de la legislación de Colombia, de los tres períodos que cubren la investigación, sobre los imaginarios que identifican la historia cultural de la colonia en especial el referente a la expedición Botánica y la relación de ésta con la Independencia americana.

La pregunta que se indica corresponde a ¿Cuáles son los contenidos e imaginarios que se han vehiculado a través de los textos escolares, en ciencias sociales, sobre la expedición botánica y que orientan hacia una nueva identidad en el imaginario de los inicios de la ciencia en Colombia en el período de 1974 a 2006. Desde esta pregunta se circunscribe el método en la corriente historiográfica de la historia social de la educación comparada y en concreto en la tendencia de análisis de textos. La metodología que se aplicó se sustentó en el análisis de contenido ${ }^{3}$ de

\footnotetext{
${ }_{3}^{2}$ Proyecto financiado por la Dirección de Investigaciones. DIN, bajo el Código SGI 772.

ALZATE, Victoria y otros. (2005): El texto escolar y las mediaciones didácticas y cognitivas. Pereira. Universidad Tecnológica de Pereira. BARDIN, L. (1996): Análisis de contenido. Madrid, Ediciones Akal, Traducción César Suárez, 2 ediciones. BOZAL, V. (1987): "Las imágenes de la enseñanza, la enseñanza de la imagen", en Revista Educación N. 269. Madrid, pp. 217-243.CARDOSO ERLAM, Néstor. (2007): Los textos escolares en Colombia: dispositivos ideológicos. 1870-1931. Ibagué, RUDECOLOMBIA, Universidad del Tolima. CARDONA, Patricia. (2017): La nación de papel. Textos escolares, lectura y politica. Estados Unidos de Colombia. 1870-1876. Medellín. EAFIT. KRIPPENDOFF, K. (1997): Metodología de análisis de contenido. Teoría y práctica. Traducción de Leandro Wolfson Barcelona. Editorial Paidos, Primera impresión. SOTO ARANGO, Diana. (1993): "El encuentro de dos mundos: enseñanza y textos escolares en Colombia", en Revista Ciencias de la Educación de España, No 155, julio-septiembre de 1993, pp. 435-446.
} 
textos escolares que permitió ubicar y analizar: primero, el contexto legal educativo, autor, texto y editorial . De esta manera el contenido se ubicó en épocas y contextos político-educativos que configuran procesos de identidad socio-cultural del colombiano a través del tema de la Independencia americana. Segundo, el análisis del tema de estudio que se estableció a través de los indicadores: conceptualización de la Ilustración y Expedición Botánica; relevancia de la expedición en el inicio de la ciencia en Colombia y los vínculos con la independencia; figuras de científicos relevantes; aportación a la identidad nacional; actividades didácticas del texto y se destacó el código ideológico subyacente ${ }^{5}$.

En la iconografía ${ }^{6}$ se estableció la tipología de las figuras de Mutis y colaboradores en la Expedición Botánica. La investigación se sustentó en 56 textos que fueron seleccionados por el número de re-ediciones y la editorial. Para este análisis se seleccionaron 22 textos que presentaban el tema de estudio. Teniendo en cuenta que los textos escolares en Colombia se elaboran siguiendo las directrices educativas del Ministerio de Educación Nacional los períodos de estudio los realizamos por las rupturas de la legislación educativa. El primer período comprende de 1974 con el Decreto 080 hasta 1983. El segundo período con el Decreto 1002 de 1984 a 1993. El tercer período corresponde a la aplicación de la Ley 115 General de Educación del 8 de febrero de 1994 , como consecuencia de las nuevas políticas que estableció la Constitución colombiana en el año $1991^{8}$, hasta el año 2008 cuando se presenta el texto escolar de la "revolución educativa" del Ministerio de Educación. Por lo tanto, las leyes, Decretos, Programas, Documentos del Ministerio de Educación Nacional y los textos se convierten en las fuentes primarias del estudio.

${ }^{4}$ SOTO ARANGO, Diana. (2011): "La independencia americana en los textos escolares en Colombia", en Textos, autores y bibliotecas. 190 años de la Biblioteca Mayor de la UNC / BESTANI, Rosa M. [et.al.]. - 1a ed. - Córdoba. Universidad Nacional de Córdoba. Biblioteca Mayor, pp. 457-469.

BINI, Giorgio y otros. (1977): Los libros de texto en América Latina. México, Editorial ${ }_{6}$ Nueva Imagen, p. 16.

Se indica que las imágenes en los textos escolares "forman parte de los procesos ideológico-culturales por medio de los cuales construye la memoria de la nación mexicana" GALVÁN LAFARGA, Luz Elena (2010) "Memorias en papel. La historia como disciplina en el currículo de la escuela primaria. 1867-1940”, en Las disciplinas escolares y sus libros. México, Centro de Investigaciones y Estudios Superiores en Antropología Social. Universidad Autónoma de Morelos, Juan Pablo Editor, p.125.

Ley 115 de 8 de febrero, 1994. Decreto 1860 de 1994. Aspectos pedagógicos. Resolución 2343 del 5 de junio de 1996 (logros curriculares). De 1995 al 2005 se aplica el Plan Decenal de Educación que se rigió por la Ley 115 del 8 de febrero 1994.

${ }^{8}$ La Constitución Política de Colombia se publicó en la Gaceta Constitucional Número 127 del día jueves 10 de octubre de 1991. 
Los resultados se enmarcan en la poca relevancia al tema y a la iconografía de la Expedición Botánica. En la conclusión se estableció que la Expedición Botánica se localiza en algunos textos como una de las causas internas de la independencia; no se le da la relevancia de ser la pionera de los inicios de la ciencia en Colombia, excepto en dos textos. La figura más reconocida es la de José Celestino Mutis seguida de Caldas y están invisibilizados los sub-directores de la Expedición. El aporte a la identidad nacional es el vínculo con el conocimiento de los recursos naturales de su tierra americana.

Destacamos que los textos escolares del tercer período ingresan en la "maratón" de la evaluación escolar y se priorizan los conceptos, contenidos que marca el Ministerio de Educación Nacional donde los inicios de la ciencia en Colombia no están dentro de las prioridades de formación ni de identidad nacional.

\section{La Ilustración y la Expedición Botánica, a través de los textos escolares de 1974-2008}

\section{Primer período: Mutis desde la colonia con impacto en los criollos ilustrados}

El tema de la Expedición Botánica, en los textos escolares de este primer período (1974 a1983) se imparte en cuarto grado de primaria en la unidad de la colonia y en 4 Bachillerato y la Ilustración en 1 y 4 de Bachillerato. De los cinco textos analizados, tres pertenecen a la Editorial Bedout y dos a Norma que corresponden a las editoriales que predominan en el mercado del texto escolar de sociales. Los textos que presentan mayores re-ediciones corresponden a los autores: Ocampo con la Editorial Bedout y Montenegro con la Editorial Norma ${ }^{10}$.

El tema de la Ilustración, en la editorial Norma, en los textos de los autores Montenegro y de Peña ${ }^{11}$, se identifica como el movimiento de la

\footnotetext{
${ }^{9}$ La primera edición es de 1774. OCAMPO LÓPEZ, Javier. (1984): Historia de Colombia. 4 grado. Medellín, Editorial Bedout. 14 reediciones. El tema de la Expedición Botánica se trata en el apartado de la vida cultural y artística de la colonia, p.141.

MONTENEGRO, Augusto. (1976): Historia de América. Bogotá, Editorial Norma. $\mathrm{El}$ autor era en ese momento director del Departamento de Historia y Geografía de la Universidad Javeriana y con un doctorado en Ciencias Sociales de la Universidad de La Habana, p. 250.

PEÑA, Margarita y MORA, Carlos Alberto. (1983): Historia de Colombia. Introducción a la bistoria social y económica. Bogotá, Editorial Norma, p. 200.
} 
razón con influencia en la revolución francesa y americana. Se indica a la Ilustración como "un movimiento intelectual que criticó la mentalidad y las estructuras políticas, económicas y sociales existentes" caso neogranadino es relevante porque "desarrolla las ciencias y se dio importancia a las ciencias útiles" ". Por otro lado, en la editorial Bedout, con González y Ruiz ${ }^{15}$ este tema de la Ilustración es tratado como un movimiento "cultural y literario" de origen francés o sencillamente se le determina como la "edad de la razón" que repercute en América pero con características propias.

En los textos señalados la relación de la Ilustración con la independencia se correlaciona con la Enciclopedia porque se indica que contribuyeron sin proponérselo a la revolución francesa y a la independencia de América" . Asimismo, considera uno de los textos que "entre los criollos que asimilaron la nueva ideología figuraba Antonio Nariño de la Nueva Granada"19.

Resulta interesante encontrar que la Expedición Botánica, se conceptualiza de manera similar en los textos de Bedout y de Norma. $\mathrm{Y}$ en este sentido se identifica como la entidad que se sustenta en la botánica que es una ciencia con "elementos exclusivamente europeos" Además, se insiste en una idea fundamental, respecto al objetivo central de la Expedición, de "estudiar la flora, la fauna y todos los recursos del

\footnotetext{
${ }^{12}$ Véase un completo estudio en la colección la "Ilustración en América colonial" SOTO ARANGO, Diana; PUIG-SAMPER, Miguel Ángel; ARBOLEDA, Luis Carlos. (1995): SOTO ARANGO, Diana. (1994): La Ilustración en las Universidades y Colegios Mayores de Santa Fe, Quito y Caracas. Bibliografía crítica y fuentes. SOTO ARANGO, Diana; PUIG-SAMPER, Miguel Ángel; BENDER, Martina; GONZÁLEZ RIPOLL, María Dolores. (2002): Recepción y difusión de textos Ilustrados. Intercambio cientifico entre Europa y América en la Ilustración.

${ }_{14}^{13}$ MONTENEGRO, Augusto. (1976): óp., cit, p. 124.

${ }_{15}^{14}$ Ibídem, p. 124.

${ }^{15}$ GONZÁLEZ MEJÍA, Conrado y ARROYAVE MEJÍA, Luis Carlos. (1975): Historia Universal. Bogotá, Editorial Bedout, texto para tercero Bachillerato, 303 pp. RUIZ, Jorge Francisco. (1983): Historia de Colombia. 4. Curso de enseñanza media. Medellín, Editorial BEDOUT, 156 pp. Unidad 7 "La Cultura en el Nuevo reino de Granada: el desarrollo de las artes, ciencias y educación" subtítulo "Las ciencias" pp. 54 a 56.

RUIZ, Jorge Francisco. (1983): Historia de Colombia. 4 Curso de enseñanza media. Medellín, Editorial BEDOUT, 156 pp. Unidad 7 "La Cultura en el Nuevo Reino de Granada: el desarrollo de las artes, ciencias y educación" subtítulo "Las ciencias" pp. 54 a 56.

GONZÁLEZ MEJÍA, Conrado y ARROYAVE MEJÍA, Luis Carlos. (1975): Historia Universal. Bogotá, Editorial Bedout, en Unidad 17, tema: "Europa en los siglos", pp. 198-199.

${ }_{19}^{18}$ MONTENEGRO, Augusto. (1976): óp., cit, pp. 125-132.

${ }^{19}$ MONTENEGRO, Augusto. (1976): óp., cit, p.128.

${ }^{20}$ PEÑA, Margarita y MORA, Carlos Alberto. (1983): óp., cit, p. 102.
} 
Nuevo Reino y así poder clasificar plantas y encontrar las que podrían servir para la medicina". Como es de suponer se sitúa de eje fundamental al "sabio" José Celestino Mutis ".

Precisamente, conviene destacar que a José Celestino Mutis ${ }^{22}$ se le considera una figura que impulsó la identidad nacional. Se le identifica como: "sabio sacerdote español que organizó y dirigió lo que habría de ser un semillero de científicos y de patriotas" $"$. Pero si hubiera que subrayar lo más significativo que señalan estos dos textos habría que referirse al hecho que muestran "que gracias al sabio español José Celestino Mutis (1732-1808) ${ }^{24}$, los criollos comenzaron a valorar y a preocuparse por aprender más sobre las riquezas que tenía la Nueva Granada" ${ }^{25}$.

Hay que añadir que dentro de los miembros de la Expedición Botánica se reconoce la presencia destacada de Francisco José de Caldas. En un segundo plano quedan Eloy Valenzuela, Pedro Fermín Vargas, Francisco Javier Matiz. Se presenta invisibilidad a la figura de Francisco Antonio Zea quien fuera subdirector de la Expedición Botánica y primer vice-presidente de la nueva República ${ }^{26}$.

Por ello es necesario valorar en su justa medida la relación indirecta que los textos le proporcionan a la independencia con la Expedición Botánica. Estos textos consideran que la Expedición estimuló en las gentes la idea de que tenemos un país con grandes riquezas. Asimismo porque a ella pertenecieron "las personas que luego hicieron la independencia" . Hito importante es que los textos lamentan que tras la guerra de la independencia se interrumpieron las labores iniciadas por los miembros de la Expedición Botánica .

${ }^{21}$ OCAMPO LÓPEZ, Javier. (1984): óp., cit, p. 121.

${ }^{22}$ SOTO ARANGO, Diana. (2005): Mutis, educador de la élite neogranadina. Bogotá, Universidad Pedagógica y Tecnológica de Colombia. Facultad de Educación. Dirección de Investigaciones de la UPTC. RUDECOLOMBIA. Búhos Editores.

ROUX, Rodolfo Ramón de. (1984): Nuestra historia. Bogotá, Editorial Andes. 5 primaria, p. 18.

${ }^{24}$ MEISELES BERNAL, Adolfo. (1992): Senderos. La historiay su paisaje natural. 7 grado. Bogotá, Ediciones Cultural Colombiana, p. 152.

DÍAZ, Gonzalo. (1998): Orígenes. 4. Geografía, Historia, Cívica. Bogotá, Editorial Libros \&Libres., p. 205.

${ }^{26}$ SOTO ARANGO, Diana. (2000): Francisco Antonio Zea un criollo Ilustrado. Madrid, Colección Thesauros. RUDECOLOMBIA, CONUEP, Instituto Colombiano de Cultura Hispánica, Consejo Superior de Investigaciones Científicas, COLCIENCIAS, Ediciones Doce Calles, 2.000, 328 págs.

${ }_{28}^{27}$ OCAMPO LÓPEZ, Javier. (1984): óp., cit, p.124.

${ }^{28}$ PEÑA, Margarita y MORA, Carlos Alberto. (1983): óp., cit, p.107. 
En las actividades didácticas el tema relevante es el de la Ilustración. Respecto a la Expedición Botánica sólo en texto de Javier Ocampo realiza una pregunta que se resume en "habla sobre la expedición Botánica y sus principales hombres" ${ }^{29}$. En definitiva, en el imaginario de crear una identidad nacional como es de esperar le proporcionan a la Expedición el crédito de haber impactado a esta élite neogranadina en conocer sus recursos naturales y sin embargo no es un tema relevante para recordar en las actividades didácticas. Por el contrario, hay que decir que, la Ilustración si es un tema para recordar en las preguntas finales.

\section{De Mutis a Caldas en el segundo período: 1984 a 1994}

Para el análisis, de este período, se seleccionaron 15 textos $^{30}$. Los cursos donde se imparte esta temática se localizan en cuarto, quinto y séptimo grado en las unidades de la colonia y la independencia. Sin embargo, se debe mencionar que se localiza en este período una gran variedad de editoriales en los textos de ciencias sociales. Curiosamente, se localiza que la Editorial Norma continúa con el autor Montenegro ahora incluyendo a otros escritores dentro de la serie que tituló "Civilización",". La característica fundamental de este período se inicia la modalidad donde los libros se realizan en colectivo de autores. Hay que destacar que aparece al iniciar el período en 1984, la editorial Andes con el texto polémico de Rodolfo de Roux .

Puede decirse que a través de los textos seleccionados el tema de la Ilustración, se presenta en séptimo grado, no supera una página con la excepción del texto de consulta de Mora y Peña. De hecho, se conceptúa en los textos, de forma resumida que la Ilustración es un movimiento "contra

\footnotetext{
${ }_{30}^{29}$ OCAMPO LÓPEZ, Javier. (1984): óp., cit, p.123.

${ }^{30}$ En el cuarto grado de primaria: tres textos. En el quinto grado de primaria: cuatro textos. En el sexto grado: un texto: En el séptimo grado: cuatro textos. En el octavo grado: dos textos. Además, un texto de consulta.

MONTENEGRO, Augusto; SALGUERO CUBIDES, Jorge; FEO, Vicente. (1991): Civilización 7. Bogotá Norma, 379 pp. MONTENEGRO GONZALEZ, Augusto; ROJAS, Inés Elvira; SALCEDO, Mariela. (1993): Civilización 6. Ciencias Sociales integradas. Bogotá, Norma. 304 pp.

El autor fue amenazado de muerte por los paramilitares y salió del país al año siguiente. ROUX, Rodolfo Ramón de. (1984): Nuestra historia. Bogotá, Editorial Andes. 5 primaria. $160 \mathrm{pp}$. Tema de la independencia $53 \mathrm{pp}$. Indica que "ha sido escrito de acuerdo con los programas vigentes del Ministerio de Educación Nacional y según los lineamientos generales del nuevo Currículo que inspira el Decreto 1002 del 24 de abril de 1984. Presenta diseño novedoso con fuentes documentales.

MORA, Carlos Alberto y PEÑA, Margarita. (1985): óp., cit, p. 97.
} 
la mentalidad y las estructuras económica, social y política imperante"34 que tiene como eje central la razón. Para unos Ilustración es sinónimo de Racionalismo ${ }^{35}$. En el discurso que se utiliza para los escolares, de quinto grado, se utiliza la expresión cabeza como sinónimo de razón . Para otros es un movimiento que surge de Francia con objetivos de cambios políticos y sociales . "Sólo tres textos consideraron que ejerció "influencia para realizar las expediciones botánicas" ". Debemos indicar que en los textos de Santillana, la Ilustración se imparte como una unidad en el séptimo grado incluyendo la "Ilustración en la Nueva Granada". Por tomar una muestra de otras editoriales encontramos la de Susaeta (1992) que en la unidad 10 dedicada a las "Reformas borbónicas" se incluye "Ilustración y reforma" .

Consideramos que en la conceptualización de la Ilustración se avanza respecto al primer período. Ahora, la razón entra a proporcionar el eje central de este movimiento cultural del siglo XVIII. En la relación de la Ilustración con la independencia, sólo un texto la considera causa interna de la independencia ${ }^{41}$ y otro de manera general indica que aceleró la independencia americana .

${ }^{34}$ MORA, Carlos Alberto y PEÑA, Margarita. (1985): Historia Socio económica de Colombia.

Bogotá, Editorial Norma.

"Siglo XVIII llamado siglo de las luces debido a una nueva orientación del pensamiento que tiende a enfocar todos los acontecimientos y a enjuiciarlos a la luz de la razón... el hombre no debe aceptar otra verdad que la que dice la razón... El movimiento renovador se conoció con el nombre de Racionalismo". MEISELES BERNAL, Adolfo. (1992): 7 grado, p. 144.

"salir de la minoría de edad usando la propia cabeza" Realiza la pregunta ¿recuerda lo que decía el filósofo alemán Emmanuel Kant al explicar en qué consistía la Ilustración? ŖOUX, Rodolfo Ramón de. (1984): óp., cit, p.18.

"Movimiento intelectual que surge en Francia y cuyo objetivo era el cambio en la organización política y social-DUARTE, Pedro; HERNÁNDEZ, Lucy; MEISELES, Adolfo. (1986): 4 grado, p. 115.

"El movimiento ideológico de la Ilustración exaltó el papel de la razón como medio para alcanzar la felicidad y el progreso humano, estimuló la investigación científica de la naturaleza y criticó la educación tradicional de las iglesias cristianas. La Ilustración surgió en Francia, entre burgueses y nobles de ideas avanzadas y se difundió por medio de la Enciclopedia MONTENEGRO, Augusto; SALGUERO CUBIDES, Jorge; FEO, Vicente. (1991): Civilización 7, p. 354. Véase en DUARTE, Pedro; HERNANDEZ, Lucy; MEISELES, Adolfo. (1986): óp., cit, p.116. MORA, Carlos Alberto y PEÑA, Margarita. (1985): óp., cit.

CASTELLOTE, Alfredo; PEÑA, Guillermo; PULLAS, Jaime; PULIDO, Martha. (equipo de colaboradores en ilustraciones) (1991): Ciencias Sociales 7. Bogotá, Editoriales Santillana S.A. Aguilar, Altea, Taurus, Alfaguara. En el libro no se especifica información de los autores. 240 pp. Dedica 8 pp. Tema de la independencia se titula "la independencia de América Latina". La Unidad 16 se titula "La Ilustración” pp. 180 a 191.

REYES CÁRDENAS, Catalina; GARCÍA, Oscar; ORTÍZ MESA, Luis. (1992): Hombres, espacio y tiempo 7 grado. Medellín, Editorial Susaeta ediciones \& cía. Ltda. ${ }_{42}^{41}$ DÍAZ RIVERO, Gonzalo; BERDUGO PALMA, Libardo. (1982): óp., cit, p. 93.

42 "muchas ideas de la Ilustración impulsaron el ánimo revolucionario... aceleró la independencia de las colonias españolas y portuguesas de América". MONTENEGRO, Augusto; SALGUERO CUBIDES, Jorge; FEO, Vicente. (1991): Civilización 7, p. 315. 
Por otra parte, conviene destacar que el tema de la Expedición Botánica, ocupa uno o dos párrafos. Se conceptúa sobre la misma de diferente manera o similar. Para la editorial Norma y Editorial el CID corresponde a "la empresa científica más importante del período colonial en la Nueva Granada. En otros textos como el de Editorial Cultural se relaciona la Expedición Botánica como: "movimiento intelectual renovador, basado en el estudio crítico de la naturaleza por parte de la juventud criolla" de investigación en botánica, zoología, mineralogía y meteorología" además que clasificaron 6.000 plantas" ". La editorial Andes con el autor Roux señala que fue "semillero científico y de patriotas" Editorial Norma relaciona la Expedición Botánica dentro de la política de Carlos III. El objetivo de la Expedición lo centran en: "recorrer el territorio del virreinato, para efectuar un inventario de recursos naturales, conocer la geografía y hacer observaciones astronómicas" ${ }^{48}$. No deja de ser curioso que se indique que la Expedición "refleja el interés de los Borbón por encontrar recursos que sustituyeran la decadente producción de oro" ". Por lo visto el mensaje que se desea vehicular es que la Expedición fue una empresa científica y un medio para el desarrollo económico dentro de la política de Carlos III.

Hay que añadir además, que sólo localizamos los textos, de Editorial Stella, que relaciona la Expedición Científica como causa interna de la independencia ${ }^{50}$ y se reitera que fue una de las mejores iniciativas para conocer los recursos naturales de América . Por otra parte, Editorial Andes relaciona la Expedición con el Movimiento de la Ilustración el

43 "Mutis dio el nombre de la Expedición Botánica a la empresa científica para la cual solicitaba permiso y financiación. Reportó valiosos descubrimientos tales como el hallazgo y clasificación de plantas útiles para la salud y la industria. Por ej. El guaco, ipecacuana, quina, té, etc."...Véase en DÍAZ RIVERO, Gonzalo; BERDUGO PALMA, Libardo. (1982): óp., cit, El Cid, p. 94. MORA, Carlos Alberto y PEÑA, Margarita (1985): óp., cit. Ed. Norma, p. 105.

${ }_{45}^{44}$ DUARTE, Pedro; HERNÁNDEZ, Lucy; MEISELES, Adolfo. (1986): óp., cit, p. 116

${ }_{46}^{45}$ DUARTE, Pedro; HERNÁNDEZ, Lucy; MEISELES, Adolfo. (1986): óp., cit, p. 116

${ }^{46}$ MEISELES BERNAL, Adolfo. (1992): MEISELES BERNAL, Adolfo. (1992): 7 grados, p. 152.

${ }_{48}^{47}$ ROUX, Rodolfo Ramón de. (1984): óp., cit p. 18

${ }_{49}^{48}$ MORA, Carlos Alberto y PEÑA, Margarita. (1985): óp., cit, p.106.

${ }_{50}^{49}$ Ibídem., p. 106.

MANTILLA DE VALDERRAMA, Hilda y LEYVA DE BECHARA, Ofelia. (1986): p. 52.

MONTENEGRO, Augusto; SALGUERO CUBIDES, Jorge; FEO, Vicente. (1991): Civilización 7. p. 354. 
de la independencia ${ }^{52}$. No obstante, se desarrolla el imaginario que las expediciones son de origen francés porque España era sumamente atrasada. Afirmación que se da a través de una cita de Mutis que se expresa en el texto de la editorial Cultural ${ }^{53}$.

Resulta interesante encontrar que al nombrar a Mutis se localiza un común denominador: "sabio, sacerdote, español" ${ }_{55}^{54}$ que vivió en América durante la época colonial ${ }^{55}$. Aún hay otra distinción en otros textos al considerar a Mutis con cualidades de administrador y por supuesto por sus conocimientos de botánica, astronomía, medicina, matemáticas, física, e historia natural que lo hicieron acreedor para dirigir la Expedición Botánica $^{56}$. Por otra parte, se le considera como el personaje que impulsó la identidad nacional y que "organizó y dirigió lo que habría de ser un semillero de científicos y de patriotas"

Resulta evidente, en los textos escolares, al indicar que los integrantes de la Expedición Botánica, fueron la primera generación de científicos de Colombia ${ }^{58}$. El personaje al que se le da más relevancia es a Francisco José de Caldas y ahora, en este período de análisis, se le ubica en el mismo nivel de Mutis al darle el distintivo de "sabio" algunos textos la presencia de Eloy Valenzuela ${ }^{60}$ y se ubican personajes que no tuvieron relación directa con la Expedición como es el caso de José Félix de Restrepo . En general, se nombra a: Valenzuela, Francisco

${ }_{53}^{52}$ ROUX, Rodolfo Ramón de (1984): óp., cit, p. 18.

53 "A imitación del Borbón francés, el español resolvió crear también la Expedición Botánica en la Nueva Granada, frente a la cual el Arzobispo-virrey Caballero y Góngora coloco a Mutis... quien afirmó que no miremos nuestra España atrasada, miremos a Europa sabia". MEISELES BERNAL, Adolfo. (1992): Civilización 7 grado, óp., cit, p.152. ${ }_{55}^{54}$ ROUX, Rodolfo Ramón de. (1984): óp., cit, p. 18.

${ }^{55}$ Considera que Mutis contaba con una formación intelectual admirable: sacerdote, físico, matemático, astrónomo, humanista, médico y sobre todo un amante conocedor de la botánica", DÍAZ RIVERO, Gonzalo, BERDUGO PALMA, Libardo. (1982): óp., cit, p. 93.

${ }_{57}^{56}$ MORA, Carlos Alberto y PEÑA, Margarita. (1985): óp., cit, p. 105.

${ }^{57}$ ROUX, Rodolfo Ramón de. (1984): Nuestra bistoria. Bogotá, Editorial Andes. 5 primaria, p. 18. MEISELES BERNAL, Adolfo. (1992): Senderos. La historia y su paisaje natural. 7 grado. Bogotá, Ediciones Cultural Colombiana, p. 152. DUARTE, Pedro; HERNÁNDEZ, Lucy; MEISELES, Adolfo. (1986): óp., cit, p. 116. MANTILLA DE VALDERRAMA, Hilda y LEYVA DE BECHARA, Ofelia. (1986): óp., cit, p. 52. tenían la idea que en las ciencias naturales y experimentales se encontraba el instrumento más adecuado para conocer los variados recursos naturales y transformar la realidad económica y el progreso de la sociedad. ROUX, Rodolfo Ramón de. (1984): p. 18.

${ }_{60}^{59}$ DÍAZ RIVERO, Gonzalo; BERDUGO PALMA, Libardo. (1982): óp., cit, p. 94.

${ }^{60}$ Cuando se indica a Valenzuela se señala como "otros investigadores" por ejemplo en: MORA, Carlos Alberto y PEÑA, Margarita. (1985): óp., cit, p. 106.

DÍAZ RIVERO, Gonzalo; BERDUGO PALMA, Libardo. (1982): óp., cit, p. 94. 
Javier Matiz, Pedro Fermín Vargas, Jorge Tadeo Lozano y empieza a figurar Francisco Antonio Zea. De ellos se dice que son las "cabezas mejores pensantes de nuestro territorio" que van "tomando conciencia nacionalista al darse cuenta de que esos recursos naturales no son aprovechados por los hijos de estas tierras sino por los españoles" ${ }^{63}$.

En definitiva, en este período se localiza la imagen positiva sobre Mutis y el hecho que por sus enseñanzas permitió desarrollar un grupo de criollos científicos que se vincularon al proceso de la independencia. Continúa predominando la figura de Caldas pero ahora con la denominación de "sabio" categoría que sólo se le otorgaba a Mutis. Aparece en este período el nombre de Francisco Antonio Zea en cuatro textos.

La aportación para la identidad nacional la encontramos en la relación de la Expedición Botánica con la independencia. El planteamiento protagónico se centra en demostrar que "gracias a las enseñanzas de Mutis y los conocimientos adquiridos en esta expedición, los criollos comenzaron a valorar y a preocuparse por aprender más sobre las riquezas que tenía la Nueva Granada" ${ }^{64}$. De allí se toma conciencia de la "libertad y la dignidad humana por lo cual no vacilaron en luchar contra la infame dominación española" ". En definitiva, para algunos se convierte la Expedición Botánica en una causa interna de la independencia ${ }^{66}$. Hay que tener en cuenta que se desarrolla la identidad en comparación con el otro. En este caso resulta evidente que se resalta la capacidad científica de los criollos y se utiliza términos como "luchar", infame dominación española", "recelo contra los explotadores extranjeros"

${ }_{63}^{62}$ DÍAZ RIVERO, Gonzalo; BERDUGO PALMA, Libardo. (1982): óp., cit, p. 94.

${ }_{64}^{63}$ MEISELES BERNAL, Adolfo. (1992): 7 grado, pp.153 y 153.

${ }^{64}$ DÍAZ, Gonzalo. (1998): Orígenes. 4. Geografía, Historia, Cívica. Bogotá, Editorial Libros \& Libres., p. 205.

${ }_{66}^{65}$ DÍAZ RIVERO, Gonzalo; BERDUGO PALMA, Libardo. (1982): óp., cit, p. 94.

${ }^{66}$ S/A (1986): Historia de Colombia. 21. "les ayudo a amar más a su patria... se comprometieron en la lucha por la independencia, muriendo varios de ellos en el patíbulo durante el régimen de terror. ROUX, Rodolfo Ramón de. (1984): óp., cit, p.18. MANTILLA DE VALDERRAMA, Hilda y LEYVA DE BECHARA, Ofelia. (1986): óp., cit, p. 23.

${ }_{68}^{67}$ DÍAZ RIVERO, Gonzalo; BERDUGO PALMA, Libardo. (1982): óp., cit, p. 94.

68 "infundió a los granadinos admiración por su tierra dotada de extraordinaria riqueza y recelo contra los explotadores extranjeros". MANTILLA DE VALDERRAMA, Hilda y LEYVA DE BECHARA, Ofelia. (1986): óp., cit, p. 52. DUARTE, Pedro; HERNÁNDEZ, Lucy; MEISELES, Adolfo. (1986): óp., cit, p. 117. 
Las actividades didácticas se centran en: frases de recordar, preguntas de evaluación, actividades de grupo en el salón de clase y actividades fuera de clase. Inician algunos textos con objetivos al iniciar la unidad. De los quince textos sólo dos nombran la Expedición en las actividades de evaluación por lo que se deduce que no es un tema de relevancia para recordar.

\section{E1 sabio Caldas personaje central en el tercer período: 1994 a 2008}

En este período para el análisis se tomaron 36 textos $^{69}$ de cuarto, quinto, séptimo y octavo grado. Las editoriales que continúan en el mercado con el mayor número de re-ediciones y textos corresponden a Voluntad y Norma. No obstante, Santillana aparece con el mayor número de textos y según las librerías de Bogotá se identifica a esta editorial con las ventas más altas en los textos de sociales.

En este período, resulta evidente el cambio de diseño en los textos escolares. Ahora, éstos podemos considerarlos textos didácticos con mínimo de contenido, reducción de páginas y variadas actividades. De esta manera, se encuentra que, las actividades son las que ocupan la mayoría de las páginas del texto. Debo reconocer que en el Seminario que dictó el Dr. Ángel Díaz Barriga comprendí que los textos escolares no se orientaban hacia una didáctica específica, sino por el contrario, el objetivo central se dirigía a la evaluación. Es decir, para preparar a los estudiantes, en los conceptos básicos, para los exámenes de Estado.

Como puede verse, a través de estos textos escolares, el tema de la Ilustración se concentra en el grado séptimo con la excepción de unos textos de otros grados. Cabe anotar que en la Editorial Santillana en el texto de 1995, del séptimo grado, la Ilustración se imparte como una unidad que incluye el tema de Bolívar en la Nueva Granada. Diez

\footnotetext{
${ }^{69}$ De los cuales cinco textos de cuarto grado de primaria; diez textos de quinto grado de primaria; ocho de séptimo, doce de octavo grado.

Seminario que impartió en la universidad del Cauca sobre "Currículo", del 19 al 20 de octubre del 2008, al Comité Curricular de RUDECOLOMBIA.

HENAO, José Tomás; BORJA GÓMEZ, Jaime Humberto (texto). (1995): Ciencias sociales 8 . Bogotá, Editorial Santillana S.A. Se indica que es una obra colectiva concebida, diseñada y creada por el Departamento editorial de Santillana. 256 pp. Dedica 3 pp. a la independencia y la titula "La independencia en Nueva Granada". La Unidad 15 se titula "la Ilustración", pp. 146 a 155.
} 
años más tarde en el mismo grado la Ilustración se incluye en la Unidad de Edad Moderna con dos subtemas: "en qué consistió la Ilustración y cuáles fueron las consecuencias políticas de la Ilustración" ${ }^{72}$. En el cuarto grado se presenta la "Ilustración en la Nueva Granada" como un apartado de la unidad de "Movimientos revolucionarios" ". En el quinto grado, Santillana no desarrolla este tema .

Por otra parte, en la Editorial Voluntad, el tema de la Ilustración en los textos de los años 1991 y $1997^{75}$ se ubicaba en séptimo grado en la unidad de la "revolución de occidente" enmarcado dentro de la revolución francesa. Sin embargo, se debe señalar que en el texto del 2004 desaparece esta temática. Posteriormente, en el texto del año 2005, del quinto grado, se ubica este contenido en las causas externas a la independencia. Dentro de este contexto, la Ilustración se conceptualiza como "un movimiento cultural, que se originó en Francia, que ponía como base de todas las acciones humanas a la razón"

Por otra parte, en la Editorial Norma y en concreto con el autor Montenegro (1994) se continúa con la línea de la incidencia de la

${ }^{72}$ RUEDA, Wilson Raúl; TANÁCS, Erika. (2004): Contextos sociales 7. Bogotá, Editorial Santillana, $255 \mathrm{pp}$. En las preguntas no se relaciona la Ilustración.

3 GÓMEZ DE BARUFFOL, Fanny Cecilia. (1999): Ciencias sociales 4. Bogotá Editorial Santillana S.A. La autora en ese momento tenía una licenciatura en Educación Básica Primaria de la Universidad Javeriana de Bogotá y profesora de las cátedras Organizaciones Sociales y Sectores Sociales, en el Instituto Superior de educación social y profesora de Ciencias Sociales en Varias escuelas de la ciudad de Bogotá. Además había publicado hasta ese entonces cuatro libros titulados Sociales 3 y 4; Colombia mía 5; Aprender Democracia 5; Sociedad 3,4,5, todos de editorial Santillana.176 pp. Dedica la unidad 10 a "Movimientos revolucionarios" con el subtema "La Ilustración en la Nueva Granada”, pp. 124 a 137.

${ }^{74}$ RODRÍGUEZ CLAVIJO, María Mercedes; BARRAGAN PULIDO, Zyomara; SIERRA PINEDO, Ana Margarita; ORTIZ JIMÉNEZ, José Guillermo. (2006): Amigos de las ciencias sociales. 5 grado. Bogotá, Editorial Santillana, 128 pp. Independencia, en la unidad 6 "Colombia en el Siglo XX". "La independencia nacional" pp. 84 -85. En las librerías de la Panamericana de Bogotá manifestaron en el 2009 que era el libro más vendido en ese grado para Sociales.

GALLEGO GARCÍA, Germán y ZARAMA, Rosa Isabel. (1997): legado 7. Bogotá, Editorial Voluntad S.A. El docente Germán Gallego en ese momento tenía una licenciatura en Ciencias Sociales de la Universidad Pedagógica Nacional y la docente Rosa Zarama era Historiadora de la Universidad Javeriana y tenía una Maestría en Relaciones Internacionales de la Universidad Javeriana. 336 pp. Dedica 20 pp. al tema de la independencia y la titula "Bolívar en marcha hacia Boyacá". El tema de la Ilustración se imparte en el Proyecto 4 y se titula el tema: "Las nuevas ideas y la Ilustración", pp. 174 a 176.

RUBIO BORBÓN, Rocío. (2005): Lideres. Ciencias Sociales Integradas 5 grado. Bogotá, Editorial Voluntad. 256 pp. Independencia. Unidad 9 "Proceso de independencia colombiana", pp. 150 a 155. 
Ilustración para la toma de "conciencia de los criollos" ${ }^{77}$. Es curioso que esta editorial en otros autores en los años 1997 y 2004 para los grados 5 y 8 se enfocan en la revolución francesa pero no vinculan el movimiento de la Ilustración . Sin embargo, en el texto del 2001 para el 8 grado destacan la Ilustración por la incidencia en la modernización y racionalización de la administración y el impulso da las disciplinas científicas" y específicamente en las expediciones botánicas.

En otras editoriales que se presentan en los textos escolares de Sociales localizamos la de Pearson $(2000)^{80}$ que, en el séptimo grado, desarrolla las ideas políticas, económicas de la Ilustración y la enciclopedia. En el cuarto grado, la editorial Prentice Hall (1999) ${ }^{81}$, el capítulo 7 lo dedica a la Ilustración. La editorial el CID en el séptimo grado lo tituló "La Ilustración y el despertar americano" ${ }^{82}$. En definitiva, esta temática se imparte en el séptimo grado y presenta relevancia al vincularla con la razón y la incidencia en la revolución americana.

Conviene destacar que en este tercer período, el tema de la Expedición Botánica se presenta de manera aleatoria en casi todos los grados. No obstante, es en el cuarto y séptimo curso, en la unidad de "La Colonia", donde hemos localizado este contenido ${ }^{83}$. En algunos textos de quinto grado ubican la Expedición Botánica en la unidad de la independencia ${ }^{84}$.

${ }^{77}$ MONTENEGRO, Augusto; EASTMAN ARANGO, Juan Carlos; MEjÍA PAVONI, Germán; URREGO, Miguel Ángel; ROJAS DE REYES, Inés Elvira; FLORIAN FLORIAN, Imelda Teresa; FEO BASTO, José Vicente. (1994): Civilización 8. Bogotá, Norma, 360 pp. Independencia 13 p. 4 reimpresiones desde 1991.Tema de la Ilustración en el capítulo 2.

MELO LORENO, Vladimir; RODRÍGUEZ, Claudia Alicia; FEO, José Vicente; CHAUSTRE AVENDAÑO, José Vicente; OULIDO CORTÉS, Oscar. (2004): Nuevo identidades. Sociales 5. Bogotá, Editorial Norma, p. 151.

RODRÍGUEZ, Claudia Alicia; CORTÉS, José David; VARGAS, Marco Aurelio. (2001): Espacios 8. Primera parte: Historia. Bogotá, editorial Norma, p. 106.

GUERRERO VILLAGRÁN, Manuel; HERNÁNDEZ GÓMEZ, Nancy. (2000): Horizontes Sociales.7 grado. Bogotá, Editorial Pearson Educación de Colombia, pp. 288 a 294.

CAMPOS H., Jaime E; ESGUERRA H., Claudia P. (1999): Horizontes sociales 4. Bogotá, Editorial Prentice Hall de Colombia Ltda., pp. 218 a 227.

${ }^{82}$ DÍAZ PERIS, Víctor. (editor). (2000): El ascenso de la Humanidad 7. Bogotá, Editorial El Cid. El tema "El siglo de las luces y su reflejo en América" comprende, pp. 106 a 114.

DÍAZ RIVERO, Gonzalo. (1998): Orígenes. 4. Geografía, Historia, Civica. Bogotá, Editorial Libros \& Libres pp. 193, 194 dedicadas a la Expedición Botánica. El texto presenta en total 240 págs.

${ }^{84}$ De los diez textos analizados, de quinto grado, dos se refieren al tema de la Expedición en la unidad de la independencia. RUBIO BORBÓN, Rocío (2005): Líderes. Ciencias Sociales Integradas 5 grado. Bogotá, Editorial Voluntad, p.151. LÓPEZ VILLA, Jorge Octavio. (2008): Ciencias sociales y competencias ciudadanas. 5. Bogotá, Ministerio de Educación Nacional, Revolución educativa, Colombia Aprende, p. 58. 
En el octavo grado, sólo en dos textos se localizó una referencia a la Expedición Botánica en la unidad de "Cultura, ciencia y educación"

Destacamos por su entidad que este tema de la Expedición Botánica, aparece en forma de cuadro sinóptico en el cuarto grado en la unidad de la colonia ${ }^{86}$. Predomina el discurso didáctico, por medio de preguntas: ¿Qué era?, ¿Quiénes la dirigieron?, ¿Qué se logró?. Dentro de este contexto, se define en la editorial libros y libros como "una expedición científica que tenía como fin conocer la geografía, las plantas y animales de la Nueva Granada. Además, realizaba y promovía las observaciones astronómicas" ${ }^{87}$. Hay que decir, que esta editorial vincula a la Expedición con las ideas de libertad y de independencia.

En tal sentido, Editorial Voluntad (2005), en el quinto grado, ubica el tema de la Expedición Botánica en la unidad de "proceso de independencia colombiano". Se conceptualiza que "bajo la dirección del científico español José Celestino Mutis, un grupo de criollos destacados en el campo de las ciencias, recorrió el territorio de la Nueva Granada, para llevar a cabo un estudio de las diferentes especies vegetales y animales que había en los distintos lugares" $"$.

Por su parte, Editorial Norma en el texto de 8 grado de 1997, en la unidad del desarrollo científico en América, el único personaje que destaca es al sabio Francisco José de Caldas y establece la pregunta de ¿Cuál fue el aporte científico del sabio Caldas a Colombia? ${ }^{89}$ En cambio en el texto del año 2001 para el mismo grado 8 destaca a José Celestino Mutis por haber creado en 1783 la primera experiencia científica moderna de Colombia. Curiosamente a Caldas sólo lo nombran como encargado de la sección de astronomía y se le destaca porque fue ejecutado por Morillo durante la conquista .

${ }^{85}$ RODRÍGUEZ, Claudia Alicia; CORTÉS, José David; VARGAS, Marco Aurelio. (2001): Espacios 8. Primera parte: Historia. Bogotá, Editorial Norma. Tema 26, p.184.

DÍAZ, Gonzalo. (1998): Orígenes. 4. Geografía, Historia, Cívica. Bogotá, Editorial Libros \& Libres.

${ }_{88}^{87}$ DÍAZ, Gonzalo. (1998): óp., cit, p.193.

${ }^{88}$ RUBIO BORBÓN, Rocío. (2005): Lideres. Ciencias Sociales Integradas 5 grado. Bogotá, Editorial Voluntad, p. 151.

RAMOS PEÑUELA, Clara Inés y ESPINOZA PULIDO, Olga Constanza. (1999): Milenio 8. Bogotá, Grupo Editorial Norma. Primera edición de 1991. 288 pp. Independencia: 8 pp. Se da un reconocimiento a MONTENEGRO Augusto por "haber permitido la utilización de sus conceptos, periodizaciones y explicaciones que aparecen en... (otros libros) de su autoría", p. 192.

RODRÍGUEZ, Claudia Alicia; CORTÉS, José David; VARGAS, Marco Aurelio. (2001): óp., cit, pp. 184-185. 
Es relevante que en el texto oficial del Ministerio de Educación Nacional para el quinto grado, la Expedición Botánica se reduce a un comentario general dentro del tema de la independencia. Allí se conceptúa que "un sabio español llamado José Celestino Mutis organizó la Expedición Botánica" ". En definitiva, en el séptimo grado se localiza un comentario desde la unidad de la colonia. En el octavo grado se define la Expedición como "la primera experiencia científica moderna de Colombia",

La importancia de la Expedición Botánica se da en cuatro apartados, en la Editorial Libros y Libres, en el cuarto grado del año 1998: "salir del atraso y desconocimiento sobre las riquezas naturales de nuestro país; reunir personas que compartían ideas de libertad e independencia de España; descubrir plantas útiles para la salud y la industria; se construyó el observatorio astronómico" ". Desde luego, en la editorial Voluntad, en el quinto grado del año 2005, se orienta a resaltar que reconocieron la naturaleza y pudieron observar la vida social, política, cultural y

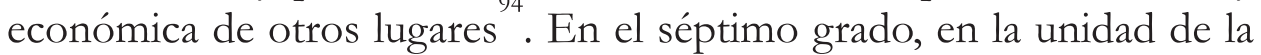
Colonia, se ubica la Expedición Botánica como la experiencia científica para conocer los recursos naturales. En la Editorial Norma en el octavo grado del 2001, en la unidad de "ciencia y cultura" se considera la expedición como "la primera experiencia científica de Colombia" y resaltar los descubrimientos que se dieron en la flora, la elaboración de herbarios y el comercio de las plantas ${ }^{96}$. Mas aún, no relacionan el tema con la independencia.

Ahora bien, se hace necesario conocer que la figura de Mutis pierde relevancia del primer y segundo período. Ya no se le indica a este personaje como el "sabio" sino simplemente Mutis o José Celestino Mutis, excepto en un texto que se le da el tratamiento de "científico".

${ }^{91}$ LÓPEZ VILLA, Jorge Octavio. (2008): Ciencias sociales y competencias ciudadanas. Bogotá, Ministerio de Educación Nacional, Revolución educativa, Colombia aprende, p. 58.

RODRÍGUEZ, Claudia Alicia; CORTÉS, José David; VARGAS, Marco Aurelio. (2001): Espacios 8. Primera parte: Historia. Bogotá, editorial Norma, p.184.

"Se indica que se realizo un herbario con 20.000 plantas. DÍAZ, Gonzalo. (1998): óp., cit, p.193.

${ }_{95}^{94}$ RUBIO BORBÓN, Rocío. (2005): óp., cit, p.151.

${ }^{5}$ RODRÍGUEZ, Claudia Alicia; CORTÉS, José David; VARGAS, Marco Aurelio. (2001): Espacios 8, p. 184.

RODRIGUEZ, Claudia Alicia; CORTÉS, José David; VARGAS, Marco Aurelio.

(2001): óp., cit, p. 184. 
El apelativo de "sabio" queda reservado principalmente para Francisco José de Caldas.

Respecto a quienes participaron en la Expedición Botánica, se localiza, en uno de los textos, una resumida biografía de: Mutis, Caldas, Lozano, Matis y Zea. Se desconoce a Eloy Valenzuela ${ }^{97}$. Al único que le concede un calificativo es al "sabio Caldas". No deja de ser curioso que confundan en la biografía a Zea con Matis . En el quinto grado no se nombran los participantes en la Expedición y en el octavo grado se incluye a Sinforoso Mutis. Pero en efecto el gran desconocido es la figura del primer subdirector de la Expedición Botánica Dn. Eloy Valenzuela y Mantilla.

La aportación para la identidad nacional se localiza en la relación de la Expedición Botánica con la independencia. Son significativas las siguientes frases que expresan los calificativos que se le dan a la Expedición dentro del proceso de la independencia. La editorial Libros y Libros expresa que "sirvió para reunir personajes que compartían las ideas de libertad e independencia de España" y porque "los criollos comenzaron a valorar y a preocuparse por aprender más sobre las riquezas que tenía la Nueva Granada" ; El texto del Ministerio de Educación Nacional del 2008 indica que "permitió que muchos criollos descubrieran la gran riqueza natural que poseía nuestro país y pensaran en la posibilidad de convertirnos en un país independiente" ${ }^{, 100}$. Dentro de este panorama a la pregunta ¿Por qué crees que la Expedición Botánica sirvió para la independencia de nuestro país? ${ }^{101}$ Se da como respuesta, en la Editorial Norma, en el octavo grado, porque los miembros de la Expedición participaron en política, propugnaron por la separación de España ${ }_{102}$ discutieron ideas contra la monarquía española y el naciente liberalismo.

En definitiva, en este tercer período, la Ilustración es un tema fundamental en el séptimo grado y es de relevancia la vinculación que se le da con el proceso de la independencia. Por el contrario, la Expedición Botánica no tiene un grado específico y se expone en diferentes unidades.

\footnotetext{
${ }_{98}^{97}$ DÍAZ, Gonzalo. (1998): óp., cit, p.194.

${ }_{9}^{98}$ DÍAZ, Gonzalo. (1998): óp., cit, p.194.

${ }_{100}$ DÍAZ, Gonzalo. (1998): óp., cit, p.205.

${ }^{00}$ LÓPEZ VILLA, Jorge Octavio. (2008): Ciencias sociales y competencias ciudadanas. Bogotá, Ministerio de Educación Nacional, Revolución educativa, Colombia aprende, p. 58. DÍAZ, Gonzalo. (1998): óp., cit, p.193.

${ }^{102}$ RODRÍGUEZ, Claudia Alicia; CORTÉS, José David; VARGAS, Marco Aurelio. (2001): óp., cit, p.184.
} 
La figura de Mutis es la relevante en el primer y segundo período y da paso a Caldas con el apelativo de "sabio". Según las editoriales se vincula o no al proceso de la independencia. Finalmente, no deja de ser curioso, que en el texto oficial de quinto grado (2008) del Ministerio de Educación Nacional sólo se le da un párrafo a la Expedición Botánica ${ }^{103}$.

\section{La iconografía de la Expedición Botánica}

En el primer período, de los cinco textos analizados, sólo dos textos exhiben la figura de Mutis, El texto de 1983, de primero Bachillerato, presenta el rostro de Mutis en blanco y negro . Este rostro muestra a un Mutis de unos 60 años, serio, con mirada hacia abajo. El vestido de sotana es el determinante de la identificación de Mutis. El texto de Javier Ocampo de 1983, 4 primaria, presenta un retrato de Mutis hasta los hombros. Se exterioriza con vestido de sacerdote que acompaña de una toga. El rostro con mirada al frente, a color, está retocado y aparenta unos cincuenta años ${ }^{105}$.

La otra figura que se relaciona es la de Francisco José de Caldas (1768-1816) en un solo texto. A este criollo lo muestran de medio cuerpo, el rostro con mirada de frente, un corte de pelo que cubre parte de la frente y con patillas; las manos, una sobre el pecho y en la otra sostiene un papel. Está vestido de civil con biblioteca al fondo y papel en la mano y se le indica como el "sabio" Caldas ${ }^{106}$. Es decir en la categoría de científico de la época. Igualmente, se presenta las figuras de: Moreno y Escandón ${ }^{107}$, Virrey Caballero y Góngora, Carlos III y un dibujo de la flora.

En el segundo período, de los quince libros, sólo cinco presentan la figura de Mutis ${ }^{108}$, la más repetida es la figura del rostro con bonete y en la mano la lupa. En esta ocasión se agrega la figura de Mutis con plantas y libros. El texto de 1984, quinto grado, presenta un Mutis vestido de

${ }^{103}$ LÓPEZ VILLA, Jorge Octavio. (2008): Ciencias sociales y competencias ciudadanas. 5 grado, p.58

${ }_{105}^{9}$ PENA, Margarita y MORA, Carlos Alberto. (1983): óp., cit, p. 105.

105 OCAMPO LÓPEZ, Javier. (1983,1984): óp., cit, p. 122.

${ }_{106}^{106}$ OCAMPO LÓPEZ, Javier. (1983,1984): óp., cit, p. 123.

${ }^{107}$ Véase un completo estudio en SOTO ARANGO, Diana. (2004): La reforma del Plan ${ }_{108}$ Estudios del fiscal Moreno y Escandón. 1774-1779.

${ }^{8}$ Cuatro figuras en el cuarto, dos en séptimo y una en quinto grado. Se repite la figura del rostro 
sacerdote de medio cuerpo con una biblioteca y un libro en la mano. Se indica que el retrato es de autor desconocido . Esta pintura se repite en el texto de séptimo grado, de 1991, identificándolo como: "Don José Celestino Mutis, primer director de la Expedición Botánica" . El Mutis que presenta el texto de 1987, del cuarto grado, lo hace en forma gráfica de un dibujo de medio cuerpo, con un bosque de fondo y en primer plano una mano con la lupa y en la otra una flor ${ }^{111}$. El texto de cuarto grado de 1985 presenta el rostro de Mutis, en blanco y negro, con la leyenda "primer director de la Expedición Botánica de Nueva Granada" El texto de séptimo grado de 1992 presenta la pintura de Mutis en blanco y negro, sentado con el libro, la flor y la lupa . Como se puede ver la figura más repetida es la de Mutis con el rostro serio, mirada hacia abajo, con el labio de abajo salido y el imaginario que transmite es la de un sacerdote.

La otra figura que se presenta, en seis textos, es la de Francisco José de Caldas. En tres iconografías la aparición de Caldas se realiza desde el imaginario de un civil sacrificado en la guerra. En efecto, el texto de 1984, de quinto grado, se le relaciona dentro del proceso de la independencia y su figura, de cuerpo entero en posición erguido con una mano en el pecho y en movimiento, se identifica como "Caldas al patíbulo" ". Le acompañan dos soldados en movimiento uno de estos mirando a Caldas. Detrás en la pared se localiza la $\mathrm{O}$ partida que es el símbolo que ha inmortalizado en el imaginario a Caldas. Este cuadro se repite en el texto de 1987, de cuarto grado, con la diferencia que ahora ocupa más de media página y al fondo en la pared se representa la $\mathrm{O}$ partida de Caldas y se agrega la figura de un religioso franciscano que se cubre la cabeza con el gorro del hábito. Se identifica el dibujo como "Francisco José de Caldas. Amigo de la ciencia y de la causa de la independencia" ". Hay que destacar que aunque se presente sólo el rostro de Caldas, como sucede con el texto de 1986, del cuarto grado, la leyenda que identifica el retrato lo relaciona con la guerra. Bien claro queda cuando indica que: "un sabio sacrificado por el odio" ". La

\footnotetext{
${ }_{110}^{109}$ ROUX, Rodolfo Ramón de. (1984): óp., cit, p. 19.

${ }^{10}$ MONTENEGRO, Augusto; SALGUERO CUBIDES, Jorge; FEO, Vicente. (1991): óp., cit, p. 293.

DÍAZ RIVERO, Gonzalo; BERDUGO PALMA, Libardo. (1987): óp., cit, p. 93.

${ }_{13}$ MORA, Carlos Alberto y PEÑA, Margarita. (1985): óp., cit, p. 105.

${ }_{114}^{113}$ MEISELES BERNAL, Adolfo. (1992): óp., cit, p. 152.

${ }_{114}^{114}$ ROUX, Rodolfo Ramón de. (1984): óp., cit, p. 29.

${ }_{116}^{115}$ DÍAZ RIVERO, Gonzalo; BERDUGO PALMA, Libardo. (1987): óp., cit, p. 96.

${ }^{116}$ DUARTE, Pedro; HERNÁNDEZ, Lucy; MEISELES, Adolfo. (1986): Cuarto grado, p.116.
} 
única representación que se hace de Caldas con la figura del imaginario científico es la del texto de 1986, correspondiente al quinto grado, que presenta un dibujo de Caldas con un libro y el telescopio ${ }^{117}$. Las cuatro restantes figuras de Caldas presentan el rostro clásico de Caldas en blanco y negro o a color ${ }^{118}$.

De los otros miembros que aparecen en la iconografía de los textos escolares, está la de Jorge Tadeo Lozano, en tres textos con la figura del rostro en medallón . Hay que destacar, que en este segundo período, la más importante novedad, es que la iconografía incluye a otros personajes vinculados con la Expedición Botánica ${ }^{20}$ y un dibujo de la flora de la Expedición. Se identifica a: el Virrey Antonio Caballero y Góngora, en medio cuerpo con toga, en tres textos ${ }^{121}$; a Francisco Antonio $Z_{e a}{ }^{122}$ en un dibujo de medio cuerpo, vestido de civil, traje de invierno europeo, en tres textos ; ${ }^{123}$ a Carlos III con la leyenda "quien promovió a investigación científica en América especialmente en el virreinato de la Nueva Granada", en tres textos ${ }^{124} \mathrm{y}$ dos dibujos de flora ${ }^{125}$.

En el tercer periodo, de los treinta y seis textos sólo se localizó en cuatro la figura de Mutis. Se repite el rostro clásico de los períodos anteriores. Se incluye como novedad un dibujo de medio cuerpo de Mutis con una planta en una mano y en la otra un papel. Una Pintura de Mutis con libro, flor sobre el libro, Las otras figuras que aparecen son las de Caldas, Lozano, Matis, y Zea y un texto, un dibujo con un personaje desconocido con la naturaleza al fondo y con una mesa con instrumentos y plantas ${ }^{127}$.

${ }^{117}$ MANTILLA DE VALDERRAMA, Hilda y LEYVA DE BECHARA, Ofelia. (1986): óp., cit, p. 69.

${ }_{119}^{118}$ MEISELES BERNAL, Adolfo. (1992): 7 grado, p. 153.

${ }^{119}$ DUARTE, Pedro; HERNÁNDEZ, Lucy; MEISELES, Adolfo. (1986): MEISELES BERNAL, Adolfo. (1992). DÍAZ, Rivero. (1987).

SOTO ARANGO, Diana; PUIG-SAMPER, Miguel Ángel; GONZÁLEZ RIPOLL, María Dolores. (2000): Cientificos criollos e Ilustración.

${ }_{122}^{121}$ MEISELES BERNAL, Adolfo. (1992): 7 grado, p. 153

${ }^{122}$ Véase una completa Biografía en: SOTO ARANGO, Diana. (2000): Francisco Antonio Zea un criollo Ilustrado.

${ }^{23}$ Se indica: Francisco Antonio Zea: colaborador de la Expedición Botánica. DUARTE, Pedro; HERNÁNDEZ, Lucy; MEISELES, Adolfo. (1986): óp., cit, p. 116.

${ }_{125}^{124}$ MEISELES BERNAL, Adolfo. (1992): 7 grado, p. 155.

${ }^{125}$ La Pasiflora adulterina (mata de curubo) pintada por Francisco Javier Cortés. Consideramos que es Matiz en lugar de Cortés. ROUX, Rodolfo Ramón de. (1984): óp., cit, p. 19.

${ }_{127}^{128}$ DÍAZ, Gonzalo. (1998): óp., cit, p.194

${ }^{127}$ RUBIO BORBÓN, Rocío. (2005): Lideres. Ciencias Sociales Integrada 5 grado. Bogotá, Editorial Voluntad. 
En definitiva, se puede concluir que la figura más representativa es la de José Celestino Mutis y el imaginario que transmite es la de un sacerdote botánico con la lupa, una planta y/o un libro. En cuanto a Caldas el imaginario que se transmite es la de un civil científico que es llevado al patíbulo. El resto de personajes vinculados con la Expedición Botánicos son escasos y presentan sólo el rostro vestidos de civil.

\section{Actividades didácticas del texto}

El texto escolar cambia con la introducción de los nuevos medios tecnológicos sustentados en competencias. Desde esta perspectiva el texto se adapta a las nuevas condiciones de formación escolar al ingresar a la evaluación como elemento fundamental de promoción escolar y de medición para los exámenes del Estado.

En el primer período, los textos se limitan a preguntas al final de la unidad. En este caso en la unidad de la colonia sólo localizamos una pregunta relacionada con la Expedición Botánica.

En el segundo período, la actividad se centra igualmente, en preguntas para el estudiante. Al respecto no se da relevancia a los contenidos relacionados con la Expedición Botánica. Cabe anotar que en cambio sí se indican actividades "para recordar el tema de la Ilustración" ". No deja de ser curioso que en el apartado de la evaluación la única actividad que se expone sobre la Expedición Botánica es la de ubicar la fecha ${ }^{129}$.

En el tercer período, es significativo que en el 2008, año del bicentenario de la muerte de Mutis, en el texto oficial del Ministerio de Educación Nacional no se le dé ninguna relevancia a la Expedición Botánica. Parece claro que al recortar los contenidos, en efecto, la Expedición junto con los temas de cultura, en la colonia, pierde relevancia. Sólo localizamos tres preguntas que relacionaban la independencia con la Expedición Botánica.

\footnotetext{
${ }^{128}$ Ej. "Piensa y responde" de siete preguntas una sobre la Ilustración y ninguna sobre la Expedición Botánica MEISELES BERNAL, Adolfo. (1992): 7 grado, p. 154. MONTENEGRO, Augusto; SALGUERO CUBIDES, Jorge; FEO, Vicente. (1991): Civilización 7, pp. 356 y 357.

MONTENEGRO, Augusto; SALGUERO CUBIDES, Jorge; FEO, Vicente. (1991): Civilización 7, p. 357.
} 


\section{CONCLUSIÓN}

De los 22 textos escolares y 16 editoriales, que se analizaron, se localiza cambios significativos en contenidos y diseños de los mismos para los tres períodos de estudio de 1974 a 2008. Es relevante indicar que la legislación indica, en teoría, los contenidos y didácticas específicas de los textos escolares. El gran cambio conceptual en los textos de Historia y/o Ciencias Sociales se da a partir de la Constitución de 1991. Esta Constitución orienta la transformación de la educación básica y secundaria con la Ley 115 de 1994. Pero sin lugar a dudas la evolución se centra en los diseños y contenidos que vehicula la empresa editorial para los textos escolares. Lo más significativo, es que a partir del segundo período los autores individuales van desapareciendo y entra en todo su rigor en el tercer período las producciones colectivas. Por otra parte, se da un cambio significativo en el mercado editorial de los textos de sociales. En este sentido, Santillana llega al tercer período con el mayor número de ventas. Se mantienen en el mercado editorial Norma y Voluntad mientras Bedout no la localizamos en este tercer período.

Ahora bien, respecto a nuestra pregunta inicial de ¿Cuáles son los contenidos e imaginarios que se han vehiculado a través de los textos escolares en ciencias sociales sobre el tema de la Expedición Botánica y la relación con la independencia americana y que orientan hacia un imaginario de los inicios de la ciencia en Colombia en el período de 1974 a 2008?, y teniendo en cuenta los indicadores de análisis podemos concluir: que la Ilustración, es un tema casi de exclusividad de los cursos superiores. En el primer período, se localiza en los cursos que se denominaban primero y cuarto bachillerato. En el segundo y tercer período se presenta esta temática en el séptimo grado. Si bien el tema, en algunos textos, aparece de manera esporádica en otros grados, la Ilustración se conceptualiza desde un eje común: "movimiento cultural sustentado en la razón". La diferencia entre los textos radica en la relevancia de haber influenciado la Ilustración a la revolución de la independencia en la Nueva Granada.

$\mathrm{El}$ aspecto, referente a la Expedición Botánica, se concreta en el primer período en la "unidad de Colonia" en los grados cuarto y quinto. En el segundo período, el tema se aborda en las unidades de colonia e Independencia en los cursos 4, 5 y 7. En el tercer período, el tema se localiza en las unidades de independencia en los grados 4 , 5 , y 7 y en el 8 grado en la unidad de "cultura y educación". Algunos textos, muy escasos relacionan la Expedición Botánica como una de 
las causas internas de la independencia. En la mayoría de los textos a la Expedición se le resalta como el medio que ayudó a los criollos a tomar conciencia de los recursos naturales de su país y por lo tanto a cambiar de mentalidad de darse cuenta que podían administrar sus recursos naturales. Nos encontramos que, en los textos escolares analizados, los autores y editores de los textos no le dan relevancia a las biografías y plantas de la Expedición Botánica. Como lo hemos señalado, la figura de José Celestino Mutis es valorada en el primer y segundo período con adjetivos de: "sabio, sacerdote español". En el tercer período, casi la generalidad, es de señalarlo sólo con el nombre. En este tercer período, el término de "sabio" se deja casi en exclusividad para Caldas. Es así, que en rango de importancia después de Mutis o a la par se ubica a Caldas. Los grandes desconocidos en el primer período son los dos subdirectores de la Expedición Botánica: Valenzuela y Zea. En el segundo período se presenta a Valenzuela pero se vuelve a invisibilizar en el tercer período. Como hecho curioso en algunos textos presentan inconsistencias en los apellidos y confusión en las pequeñas biografías de los botánicos y pintores presentados.

Subrayando más en concreto, en la iconografía, la figura predominante se refiere a José Celestino Mutis representando al sacerdote científico que se acompaña de la lupa, planta y el libro. Se recurre a retratos clásicos del rostro de Mutis con algunos retoques de presentarlo más joven y la otra en dibujo. La segunda figura, en importancia, es la de Caldas que es representado como un civil sacrificado en la guerra. Las figuras que se representan son las clásicas del rostro y la del camino al patíbulo. En la iconografía la figura ausente es la de Eloy Valenzuela y la planta la mutisia.

Podría intentarse una explicación respecto a la vinculación de la expedición botánica con la identidad nacional a partir del conocimiento de los recursos naturales. Como lo indican los textos se facilitó el conocimiento de su naturaleza americana.

Es importante resaltar que en las actividades didácticas, referentes al recordar, se establece relevancia al movimiento cultural de la Ilustración en cambio la Expedición Botánica es la gran ausente. En definitiva, encontramos también que esta temática varía en la conceptualización y extensión según el período estudiado. Consideramos que la gran perdedora es la Expedición Botánica en los textos escolares de Sociales de Colombia. 
Por último, no deja de resultar paradójico que en la conmemoración del bicentenario de la independencia en Colombia, los textos escolares, y en especial el del Ministerio de Educación Nacional, le den una escasa relevancia al hecho histórico de la expedición Botánica y se prioriza sólo el recordar palabras claves posiblemente para los exámenes del Estado.

La pregunta que parece pertinente hoy día es ¿por qué un hecho cultural de gran importancia para la historia de la ciencia nacional se invisibiliza en los textos escolares?, y personajes como Eloy Valenzuela y Mantilla continúa olvidado y sin reconocerle los aportes que proporcionó al desarrollo cultural y educativo en los inicios de la nueva República de Colombia.

\section{FUENTES}

\section{Iconografía: Textos Escolares}

Primer período: 1974 a 1983

GONZÁLEZ MEjÍA, Conrado y ARROYAVE MEjÍA, Luis Carlos. (1975): Historia Universal, Bogotá, Editorial Bedout, texto para tercero Bachillerato.

MONTENEGRO, Augusto. (1976): Historia de América. Bogotá, Editorial Norma.

OCAMPO LÓPEZ, Javier. (1983.1984): Historia de Colombia. 4 grado. Medellín, Editorial Bedout. 14 ediciones.

PEÑA, Margarita y MORA, Carlos Alberto. (1983): Historia de Colombia. Introducción a la historia social y económica. Bogotá, Editorial Norma.

RUIZ, Jorge Francisco. (1983): Historia de Colombia. 4 Curso de enseñanza media. Medellín, Editorial BEDOUT.

\section{Segundo período 1984- 1993}

ARIAS DE CIFUENTES, Fanny María. (1992): Mi Colombia Ciencias Sociales. Grado $4^{\circ}$. Bogotá, Editorial Educativa, Ministerio de Educación Nacional: Fondo MEN Plan de Universalización de la Educación Básica primaria propiedad de la escuela.

BURGOS, Campo Elías; NAVARRO B., Ana Victoria. (1992): Sociedad Activa 7. Bogotá, Editorial EDUCAR EDITORES S.A. 
CASTELLOTE, Alfredo; PEÑA, Guillermo; PULLAS, Jaime; PULIDO, Martha. (1991): Ciencias Sociales 7. Bogotá, Editoriales Santillana S.A. Aguilar, Altea, Taurus, Alfaguara.

DÍAZ RIVERO, Gonzalo; BERDUGO PALMA, Libardo. (1987): Sociales Básica. 4 Educación Básica primaria. Bogotá. El Cid.

DUARTE, Pedro; HERNÁNDEZ, Lucy; MEISELES, Adolfo. (1986): Patria y Sociedad. 4. Nuestra Colombia. Bogotá, Editorial Cultural.

HERMANOS, Justo Ramón Florencio. (1986): Colombia. Bogotá, El Cid.

MANTILLA DE VALDERRAMA, Hilda y LEYVA DE BECHARA, Ofelia. (1986): Estudios sociales. 5. Bogotá, Editorial Stella.

MEISELES BERNAL, Adolfo. (1992): Senderos. La historia y su paisaje natural. 7 grado. Bogotá, Ediciones Cultural Colombiana.

MONTENEGRO, Augusto; SALGUERO CUBIDES, Jorge; FEO, Vicente. (1991): Civilización 7. Bogotá Norma.

MONTENEGRO GONZÁLEZ, Augusto; ROJAS, Inés Elvira; SALCEDO, Mariela. (1993): Civilización. 6. Ciencias Sociales integradas. Bogotá, Norma.

MORA, Carlos Alberto y PEÑA, Margarita. (1985): Historia Socio - económica de Colombia. Bogotá, Editorial Norma.

NOREÑA, María Isabel; GARCÍA ORTIZ, Fabio; ROJAS, Ruth Isabel. (1991): Ciencias Sociales Integradas 8.Bogotá, Editorial Voluntad S.A.

ORTIZ DE GARCÍA, Gladis; RESTREPO DE FLÓREZ, Agustiniana; CRUZ DE RODRÍGUEZ, Gloria A. (1989): Pobladores Sociales 5․ Bogotá. VOLUNTAD.

REYES CÁRDENAS, Catalina; GARCÍA, Oscar; ORTIZ MESA, Luis. (1992): Hombres, espacio y tiempo 7 grado. Medellín, Editorial Susaeta ediciones \& Cía. Ltda.

ROUX, Rodolfo Ramón de. (1984): Nuestra historia. Bogotá, Editorial Andes. 5 primaria.

\section{Tercer período 1994-2008}

ALGARRA, Patricia, y otros. (1999): Sociales interactivas 8. Bogotá, Editorial McGraw-Hill INTERAMERICANA, S.A. 
CAMPOS H, Jaime; E. ESGUERRA H., Claudia P. (1999): Horizontes sociales 4. Bogotá, Editorial Prentice Hall de Colombia Ltda.

CAMPOS H, Jaime; E. ESGUERRA H., Claudia P. (1999): Horizontes sociales 5. Bogotá, Editorial Prentice Hall de Colombia Ltda.

COLBERT, Vicky; LEVINGER, Berly; MOGOLLÓN, Oscar. (1994). Guías de aprendizaje. Escuela Nueva. Módulo 2. Ciencias Sociales y competencias ciudadanas. Bogotá. El Tiempo Colombia vive. Reedición en el 2008.

CORTÉS DE SARMIENTO, Clara Marina; ÁLVAREZ DE HUERTAS, Rubby; RODRÍGUEZ DE CASTELBLANCO, Rosaura. (1999): Ciencias Sociales 8 grado. Tunja, Imprenta Muisca.

DÍAZ RIVERO, Gonzalo. (1998): Orígenes. 4. Geografía, Historia, Cívica. Bogotá, Editorial Libros \& Libres.

DÍAZ PERIS, Víctor (editor). (2000): El ascenso de la Humanidad 7. Bogotá, Editorial El Cid.

FERRONI DE CHIAPE, Eleonora; JIMÉNEZ RODRÍGUEZ, Gonzalo. (1994): Mundo Moderno. 8 grado. Bogotá, Libros / Libres.

GALLEGO GARCÍA, Germán; ZARAMA, Rosa Isabel. (1997): Legado 7. Bogotá, Editorial Voluntad S.A.

GRANADA OSORIO, Germán. (2003): Ciencias Sociales. Propuesta curricular integrada. Educación básica secundaria. 8 grado. Bogotá, Educar Editores.

GRANADA OSORIO, Germán Antonio. (2000): Aldea 8. Bogotá, Editorial Voluntad S.A.

GUERRERO VILLAGRÁN, Manuel; HERNÁNDEZ GÓMEZ, Nancy. (2000): Horizontes Sociales. 8 grado. Bogotá, Editorial Pearson Educación de Colombia.

GUERRERO VILLAGRÁN, Manuel; HERNÁNDEZ GÓMEZ, Nancy. (2000): Horizontes Sociales.7 grado. Bogotá, Editorial Pearson Educación de Colombia.

GÓMEZ DE BARUFFOL, Fanny Cecilia. (1999): Ciencias sociales 4. Bogotá Editorial Santillana S.A.

GORDILLO, Edith Amanda y GONZÁLEZ, Clara Isabel. (2001): Épocas 5. Serie de Ciencias Sociales para el desarrollo de competencias en educación básica primaria. Bogotá, REI Andes. 
HENAO, José Tomás (director), BORJA GÓMEZ, Jaime Humberto (texto). (1995): Ciencias sociales 8. Bogotá, Editorial Santillana S.A.

IBARRA YEPES, Ana Rosalba; DÍAZ DÍAZ, Rafael. (2000): Milenio 4. Ciencias Sociales. Bogotá, Editorial Norma.

IBARRA, Ana; FEO, José; DÍAZ, Rafael. (2000): Milenio 5. Bogotá, Editorial Norma.

ISAZA RAMOS, Mary Luz. (2006): Ciencias Sociales 8. Bogotá. Empresa Enlace Editores.

LANZA, Alba Ruth; GUZMÁN, Guillermo; MARTÍNEZ CLEVES, Raúl (2003): Geografía e historia de Fusagasugá. Alcaldía de Fusagasugá.

LÓPEZ VILLA, Jorge Octavio. (2008): Ciencias sociales y competencias ciudadanas. Bogotá, Ministerio de Educación Nacional, Revolución educativa, Colombia aprende.

MONTENEGRO, Augusto; EASTMAN ARANGO, Juan Carlos; MEjÍA PAVONI, Germán; URREGO, Miguel Ángel; ROJAS DE REYES, Inés Elvira; FLORIÁN FLORIÁN, Imelda Teresa; FEO BASTO; José Vicente. (1994): Civilización. 8. Bogotá, Norma.

MORALES ÁLVAREZ, Hernando Antonio; SARMIENTO GORDILLO, Héctor Samuel. (2004): Inteligencia Social7. Bogotá, Editorial Voluntad S.A.

MORENO FERNÁNDEZ, Martha. (2003): Ciencias Sociales. Propuesta curricular integrada. 5. Educación Básica Primaria. Bogotá, Grupo editorial Educar.

MORENO FERNÁNDEZ, Martha. (2000): Aldea 7. Sociales integradas, Historia y Geografía. Bogotá, Editorial Voluntad.

OCHOA JARAMILLO, Daniel; LINARES RUBIO, Inés. (1995): Procesos Sociales 7 grado. Bogotá, Editorial Santillana S.A.

OCHOA JARAMILLO, Daniel; LINARES RUBIO, Inés. (1995): Procesos Sociales 8 grado. Bogotá, Editorial Santillana S.A.

RAMOS PEÑUELA, Clara Inés y ESPINOZA PULIDO, Olga Constanza. (1999): Milenio 8. Bogotá, Grupo Editorial Norma. Primera edición de 1991.

RIAÑO LESMES, Hernando. (2001): Aldea 4. Sociales integradas, Historia y Geografía. Bogotá, Editorial Voluntad. 
RODRÍGUEZ, Claudia Alicia; CORTÉS, José David; VARGAS, Marco Aurelio. (2001): Espacios 8. Primera parte: Historia. Bogotá, editorial Norma.

RODRÍGUEZ CALVIJO, María Mercedes; BARRAGÁN PULIDO, Zyomara; SIERRA PINEDO, Ana Margarita; ORTIZ JIMÉNEZ, José Guillermo. (2006): Amigos de las ciencias sociales. 5 grado. Bogotá, Editorial Santillana.

RUBIO BORBÓN, Rocío. (2005): Lideres. Ciencias Sociales Integradas 5 grado. Bogotá, Editorial Voluntad.

RUEDA, Wilson Raúl; TANÁC, Erika. (2004): Contextos sociales 7. Bogotá, Editorial Santillana.

RUEDA, Wilson Raúl. (2007): Nuevas Ciencias Sociales $8^{\circ}$. Bogotá. Santillana.

SOTO ARANGO, Diana. (2011): “La Expedición Botánica en los textos escolares de Colombia 1974-2008" en: Revista Historia de la Educación Latinoamericana N. 16, Tunja, Universidad Pedagógica y Tecnológica de Colombia, RUDECOLOMBIA, SHELA- HISULA pp. $225-254$ 